\title{
Oxygen-ozone and $\alpha$-lipoic acid in the treatment of peripheral neuropathies conflicting therapies or synergistic association?
}

\author{
Antonio Santo Bruno \\ Scientific Society of Oxygen-Ozone Therapy (SIOOT), Gorle (BG), Italy
}

\begin{abstract}
The report in question is divided into four parts: i) neuropathies: pathophysiology notes; ii) oxidative stress: conceptual points useful for this report; iii) lipoic acid: general characteristics with particular mention of the characteristics of the product that can influence the action of the ozone; iv) oxygen-ozone therapy and lipoic acid: conflict or synergistic association?
\end{abstract}

\section{Neuropathies}

Peripheral neuropathy can be defined as a morbid condition resulting from deterioration and a consequent functional deficit of the peripheral nerves, except for the first (olfactory) and second (optic) cranial nerves and/or their sheaths. There are numerous causes - diabetes and the forms of entrapment-compression are the main factors, at least in industrialized countries. ${ }^{1-14}$

Possible nerve sites involved in the pathogenetic process are the cell body (ventral horns or dorsal root ganglia), the axon, the myelin (Schwann cells), the vasa nervorum, and the connective tissue.

The pathogenic agent can damage Schwann cells or myelin sheaths, causing demyelination and relative saving of axons, or selectively deteriorate axons by a damaging action on the cell body or on the axolemma, or both. However, it should be noted

Correspondence: Antonio Santo Bruno, Scientific Society of OxygenOzone Therapy (SIOOT), via Don Luigi Sturzo 2, 24020 Gorle (BG), Italy. Tel:. 035.19910105.

E-mail: info@ossigenoozono.it

Key words: peripheral neuropathies; oxygen-ozone; alpha lipoic acid.

Conflict of interest: the author declares no potential conflict of interest.

Received for publication: 23 April 2018.

Accepted for publication: 24 April 2018.

(C) Copyright A.S. Bruno, 2018

Licensee PAGEPress, Italy

Ozone Therapy 2018; 3:7517

doi:10.4081/ozone.2018.7517

This article is distributed under the terms of the Creative Commons Attribution Noncommercial License (by-nc 4.0) which permits any noncommercial use, distribution, and reproduction in any medium, provided the original author(s) and source are credited. that a substantial proportion of neuropathies $(25 \%)$ do not have a recognizable cause.

Regarding treatment of peripheral neuropathies it is important to note that, in general, although neuropathic pain (in particular chronic pain) poorly responds to treatment with pure corticosteroids, NSAIDs or analgesics, currently these classes of drugs are equally and widely used in these conditions.

Therefore, once the surgical indications have not been included, the therapeutic approach includes the following treatments, which are variously associated with each other and/or with the treatment of the basic pathology: i) Pharmacological therapy with corticosteroids, anti-inflammatories, analgesics, SSRI antidepressants (selective serotonin reuptake inhibitors) or SSNRI antidepressants (serotonin and norepinephrine reuptake inhibitors), anticonvulsants, mesotherapy; ii) Physiotherapy (antalgic electrotherapy, UST, magnetotherapy, etc.); iii) Oxygen-ozone therapy; iv) Acupuncture; v) Postural re-education (generally after acute phase); vi) Chiropractic.

In the case of pharmacological therapies, so-called nutritional supplements with an antioxidant function are arousing increasing interest. In fact, a rational therapeutic approach also involves the use of neuroprotective products that have an antioxidant action, in order to improve the quality of nerve and perineural structures, the speed of nerve conduction and the endoneural blood flow, thus reducing pain, hypodysesthesia and functional limitations that generally characterize this type of illness.

The reason for the administering of antioxidants in peripheral neuropathies is to be found in the fight that all organisms face against oxidative stress.

\section{Oxidative stress}

All forms of life maintain a reducing environment within their cells; the cellular redox environment is preserved by enzymes that maintain the reduced state through a constant input of metabolic energy; oxidative stress is a pathological condition caused by the breaking down physiological balance in a living organism between the production and the elimination (by the antioxidant defence systems) of oxidizing chemical species.

However, in humans the level of oxidation-reduction of the organism can be evaluated with the d-ROMs test. The involvement of oxidation processes (ROS, Reactive Oxigen Species) in the onset and worsening of neuropathic pain has been demonstrated in numerous studies that have confirmed that oxidative stress is an important determinant of the degenerative and painful pathological conditions of peripheral nerves. Therefore treatment (pharmacological or not) for peripheral neuropathies must be able to determine as a priority a reduction or resolution of oxidative stress. 


\section{Lipoic acid}

In the context of nutritional products with recognized antioxidant functions, a fundamental role is played by some vitamins with high antioxidant power; the three most important antioxidant vitamins for their properties are vitamin $\mathrm{E}$, vitamin $\mathrm{C}$ and $\alpha$-lipoic acid (vitamin N).

$\alpha$-lipoic acid - also called lipoic acid, thioctic acid, ALA (oxidized form), DHLA (reduced form) - is a fatty acid found naturally inside each cell in the body. Its fundamental characteristics can be summarized in the following points: it is both water-soluble and fatsoluble, plays a role in glucose metabolism, reduces the concentration of excess free radicals, has been shown to counteract the degeneration linked to ageing in mitochondrial functions. Lipoic acid has direct antioxidant activities, indirect antioxidant activities and metabolic activities in the production of energy from the Krebs cycle.

The main direct antioxidant activities consist in protecting the body from free radicals (exogenous or endogenous) in excess (superoxide radicals, hydroxy radicals, hypochlorous acid, peroxiradicals, singlet oxygen, ionizing radiation, including depleted uranium inhalation in areas of previous or current military conflict) in all the compartments of the organism (intra- and extracellular), acquiring electrons.

As an indirect antioxidant activity, it gives its electron to oxidized (inactive) species regenerating other antioxidants such as vitamin C, vitamin E, coenzyme Q10 and glutathione.

As for metabolic activities in the production of energy from the Krebs cycle, this molecule is involved in the formation, from pyruvate (which, derived from anaerobic glycolysis, can be released via 3 pathways: lactic acid, acetaldehyde-ethanol, through conversion to acetylcoenzyme A, the start molecule of the Krebs cycle. Therefore, the reactions of the oxidative metabolism of carbohydrates, fatty acids and amino acids (aerobic energy chain) involving lipoic acid are: i) immediately before the beginning of the Krebs cycle: Acetyl-CoA formation (necessary for the first reaction of the Krebs cycle) from pyruvic acid through pyruvate dehydrogenase enzymatic complex; ii) Krebs cycle (8 chain reactions)4th reaction - Succinyl-CoA formation (Second oxidative decarboxylation): Oxidative decarboxylation catalyzed by a multienzymatic complex very similar to that of pyruvate dehydrogenase in terms of structure and function; $\alpha$-ketoglutarate dehydrogenase complex.

What makes it unique is that it works both in water and in fat (for this reason it is ubiquitous), unlike other antioxidants that are either hydrophilic or lipophilic.

Unlike antioxidant vitamins, ALA has antioxidant activity in both the oxidized and the reduced form. This means that, even if already oxidized, it still maintains an antioxidant function. $\alpha$-lipoic acid in the treatment of peripheral neuropathies works as an antioxidant in both water and fatty tissue, being able to penetrate every part of the neuron (including myelin sheaths and Schwann cells) and protecting them from damage, limiting the damage caused to nerve structures by free radicals, preserving them from dangerous degeneration. As a result, improving the speed of nerve communication optimizes its functionality

In conclusion, from what has been reported on lipoic acid, this molecule has been called The conductor of the orchestra of all the other major antioxidant products (or the best known).

\section{Side effects of lipoic acid}

The main side effects of $\alpha$-lipoic acid are: migraine, stinging or tingling sensation, rash, muscle cramps, autoimmune insulin syndrome (a few cases in Japan, a rare condition).

\section{Pharmacological interactions of lipoic acid}

$\alpha$-lipoic acid could influence glycaemic control by inducing hypoglycaemia; therefore, diabetic subjects who are taking oral hypoglycaemic drugs (e.g. Metformin, Glucophage, Glibomet, ...), can take $\alpha$-lipoic acid provided they monitor blood sugar more frequently. Animal studies indicate that $\alpha$-lipoic acid could alter thyroid hormone levels, so it could theoretically have the same effect on humans. Those who take drugs for hypothyroidism (Levothyroxine or similar) should therefore undergo periodic monitoring of blood thyroid hormones.

\section{Pharmacokinetics}

There are various formulations on the market with very variable Tmax, $\mathrm{T}^{1} / 2$, AUC; what interests us most is the half-life $\left(\mathrm{T}^{1} / 2\right)$, i.e. the time when the concentration of the drug is halved after the blood peak. Furthermore, there are fast-release formulations which allow rapid absorption of the drug with rapid hematic peak and others with gradual release (slow release) with maintenance of constant levels for over 10 hours; in the slide one of the slowrelease lipoic acid formulations (MATRIS technology) is shown with a blood peak after 8 hours after administration.

\section{Oxygen-ozone therapy and lipoic acid: conflict or synergistic association?}

For the purposes of this report, some aspects of ozone kinetics should be highlighted. As soon as it is introduced into the body, it immediately binds, in order of preference, to polyunsaturated fatty acids and antioxidant molecules, especially those containing thiol groups; for high doses (not reached with the concentrations that are used in medicine) it binds to carbohydrates, enzymes, DNA and RNA.

It should be noted that the molecular ozone has a notable affinity for the sulfhydryl groups inducing their oxidation. Therefore, this reaction is triggered on injection (however it is used, not only during GAET).

For example, it has a remarkable affinity for the peptide glutathione (GSH), which is transformed into the disulfide form. The oxidized GSH is then again reduced by the enzyme GSH-reductase.

Therefore, before ozone reaches the sites where metabolic reactions are triggered in response to the oxidizing stimulus, there is a partial consumption thereof - direct reaction with polyunsaturated fatty acids (PUFA) and antioxidants.

Only once carried by the bloodstream to the target organs can the molecular mechanisms of ozone that are already widely recognized be triggered. Administration by means of major autohaemotherapy produces, as final effects: i) a modulation of the immune system by the release of TNF- $\alpha$, IFN- $\gamma$, IL-2, IL- 6 leukocytes and adhesion molecules in epithelial cells of the respiratory mucosa (it could allow the endogenous reactivation of a depressed immune system due to chronic diseases or age); ii) the increase of antioxidants able to fight diseases linked to aeing (SOD, GSHPx, catalase, cerebral SOD).

With regard to ozone toxicity, in general the administered dose should not exceed the capacity that the antioxidant enzymes (superoxide dismutase and catalase) and the molecules (glutathione in particular) have, to prevent the excessive production and build-up of superoxide anion and hydrogen peroxide. However, significant concentrations of free radicals are currently found in many physiological and pathological situations: i) ageing; ii) cellular respiration; iii) peroxidation of unsaturated mem- 
brane lipids; iv) inflammatory processes; v) neoplastic transformations, etc.

However, there are mechanisms of antioxidative protection intrinsic to the body and repair that, following ozone administration, lead to the activation of enzymes appointed to inactivate free radicals.

\section{Kinetics of ozone in the body}

The half-life of ozone is shortened as temperature increases. A $+20^{\circ}$ is 40 minutes, $\mathrm{a}+30^{\circ}$ is 30 minutes.

\section{Discussion}

From a comparison regarding the kinetics of both molecules I think that, for the short time that $\mathrm{O}_{3}$ is in circulation immediately after its administration (about 25 minutes), in the organism there should not be high concentrations of exogenous lipoic acid, since the 2 molecules inactivate one another. Considering that the lipoic acid formulations on the market have a variable half-life and that there are some that maintain high blood levels for more than 12 hours after ingestion, if the therapies can be considered synergistic, the two elements cannot be administered close together.

\section{Conclusions}

In order to maximize the potential of the therapeutic induced ozone shock through the development of momentary oxidative stress, the organism should not be protected from a high blood concentration of exogenous lipoic acid and, therefore, the patient should be instructed to suspend therapy with any formulation of this product which is daily (taken 1-2 times a day) the previous day and the same day of the session of oxygen-ozone therapy, otherwise it could negatively influence the effectiveness of overall treatment.

Provided that the correct modalities of use and the therapeutic indications for both are respected, oxygen-ozone and the lipoic acid are great allies, but they must perform their actions at a suitable distance from one another.

\section{References}

1. Cazzato D. Le neuropatie periferice: inquadramento generale. 2016. Available from: http://m.docente.unife.it/enrico.granieri/ materiale-didattico/seminari-scuola-di-specializzazione-neurologia-2016-le-neuropatie-periferiche/le-neuropatie-periferiche-inquadramento-generale-dott-daniele-cazzato/view. Accessed: March 2016.

2. Watson JC, Dyck PJ. Peripheral neuropathy: a practical approach to diagnosis and symptom management. Mayo Clin Proc 2015;90:940-51.

3. León OS, Menéndez S, Merino N, et al. Ozone oxidative preconditioning: a protection against cellular damage by free radicals. Mediators Inflamm 1998;7:289-94.

4. Kilk K, Meitern R, Härmson O, et al. Assessment of oxidative stress in serum by d-ROMs test. Free Radic Res 2014;48:883-9.

5. Nelson L, Cox M. I principi di biochimica di Lehninger. Bologna: Zanichelli; 2014.

6. Pace E. Le vitamine: la chimica, la tecnica farmaceutica. L'azione biologica. I metodi industriali di estrazione e di sintesi. Milano: Hoepli; 1949.

7. Park S, Karunakaran U, Jeoung NH, et al. Physiological effect and therapeutic application of alpha lipoic acid. Curr Med Chem 2014;21:3636-45.

8. Fantozzi R. Alfa-Lipoico: Quando la formulazione può fare la differenza. Dipartimento di Scienza e Tecnologia del Farmaco, Università di Torino. GIOT 2014;296:40:296-300.

9. Ricevuti G. $25^{\circ}$ anno fondazione SIOOT - III Congresso mondiale ossigeno-ozonoterapia. 'Il futuro ha un cuore antico'. 1518 nov 2007, Bergamo, Italy.

10. Valdenassi L. Ossigeno-ozonoterapia, comprensione dei meccanismi d'azione e possibilità terapeutiche. $70^{\circ}$ congresso nazionale 'Noi, orgogliosamente medici di famiglia. Fiducia, innovazione, competenza, organizzazione'. 6-11 oct 2014, Forte Village, Santa Margherita di Pula (CA), Italy.

11. Garret RH, Grisham CM. Principi di Biochimica. Padova: Piccin Nuova Libraria; 2004.

12. Bilska A, Włodek L. Lipoic acid: the drug of the future? Pharmacol Rep 2005;57:570-7.

13. Notiziario Chimico Farmaceutico, NCF. Tecnologie a rilascio modificato: oltre i pellets. Available from: www.notiziariochimicofarmaceutico.it. Accessed: 5 apr 2017.

14. Vetro A, Mantia F, Mantia R. Terapia dei conflitti disco-radicolari. Comparazione clinica tra ossigeno-ozono terapia paravertebrale e trattamento combinato ossigeno-ozono terapia e un prodotto a base di acido alfa-lipoico. Minerva Ortopedica Traumatologica 2006;57:57-63. 